\title{
Routine Cancer Treatment Regimens and Its Impact on Fine Motor Dexterity in Breast Cancer
}

\author{
Niklas Paul Grusdat ${ }^{\mathrm{a}} \quad$ Alexander Stäuber $^{\mathrm{a}} \quad$ Marion Tolkmitt $^{\mathrm{b}} \quad$ Jens Schnabel ${ }^{\mathrm{b}}$ \\ Birgit Schubotz ${ }^{c}$ Henry Schulza \\ aProfessorship of Sports Medicine/Sports Biology, Chemnitz University of Technology, Chemnitz, Germany; \\ ${ }^{b}$ Deutsches Rotes Kreuz Krankenhaus Chemnitz-Rabenstein, German Red Cross Hospital, Chemnitz, Germany; \\ 'Tumorzentrum Chemnitz e.V., Clinical Cancer Registry Chemnitz, Chemnitz, Germany
}

\section{Keywords}

Breast cancer · Fine motor dexterity · Survivorship · Cancer treatment

\begin{abstract}
Introduction: Breast cancer can be a major challenge for those affected. Knowledge of changes in fine motor dexterity in affected women due to routine cancer therapies can help guide effective support. Methods: For this prospective observational study, we collected data of 79 women with a mean age $54.6 \pm 9.5$ years prior to, after breast cancer therapy (T1), and at 3-month follow-up. The fine motor dexterity was assessed for 4 treatment subgroups: $S C=$ Surgery + Chemotherapy, SCR = Surgery + Chemotherapy + Radiotherapy Therapy, SR = Surgery + Radiotherapy, and S = Surgery. $\boldsymbol{R e}$ sults: Over time, women with breast cancer showed significant decreases in fine motor dexterity across all treatment groups $(p<0.001)$. The strongest negative effect was seen in the treatment groups receiving additional chemotherapy. SCR group showed pronounced limitations for dominant hand $(\mathrm{DH})-12 \%$; non-dominant hand $(\mathrm{NDH})-15 \%$; both hands $(\mathrm{BH})-17 \%$; assembly (ASSY) $-11 \%$ at T1. Significant interaction was noticeable in $\mathrm{DH}(F=5.59, p<0.001), \mathrm{NDH}(F$ $=6.61, p<0.001), \mathrm{BH}(F=13.11 p<0.001)$, and ASSY $(F=5.84$ $p<0.001)$. Discussion/Conclusion: Our study showed that the extent of change in fine motor dexterity depends on the treatment regimen. The detection of unmet care needs
\end{abstract}

karger@karger.com www.karger.com/ort

Karger ${ }^{\prime \prime}=$ BOPEN ACCESS
(C) 2021 The Author(s)

Published by S. Karger AG, Basel

This is an Open Access article licensed under the Creative Common Attribution-NonCommercial-4.0 International License (CC BY-NC) (http://www.karger.com/Services/OpenAccessLicense), applicable to the online version of the article only. Usage and distribution for commercial purposes requires written permission. could help to personalize and optimize clinical and survivorship care. Based on our findings, multidisciplinary support initiated early in breast cancer therapy is required.

(c) 2021 The Author(s).

Published by S. Karger AG, Basel

\section{Introduction}

Breast cancer continues to be the most frequently diagnosed female cancer worldwide (2.26 million cases) [1]. The European Union reported 91.826 cases of death from breast cancer in 2020 [2]. In Switzerland, breast cancer is one of the most frequent cancers with 7,292 cases in 2020 [3]. Germany reports approximately 70.000 new cases every year [4]. Overall survival has improved in recent decades with new therapy options and personalized medicine [4]. Emotional challenges [5], functional limitations [6-8], cancer-related cognitive impairment (CRCI) [911], chemotherapy-induced peripheral neuropathy $(\mathrm{CIPN})[12,13]$ were all reported in women undergoing conventional breast cancer treatment. Especially at an early stage in life the ability to function in the workplace and employment issues are of great concern. Experiences may be highly individual and are sometimes underestimated in clinical routine assessments [14]. The Purdue Pegboard Test (PPT) has gained scientific credibility in measuring unimanual and bimanual finger and hand motor dexterity. In addition, it allows to draw conclusions 
regarding cerebral lesions [15], cognitive processing [16, $17]$, and on executive and social functioning $[18,19]$. Moreover, score changes have been shown to be of prognostic value in disease progression $[20,21]$ and the incidence of post-operative complications $[22,23]$.

Patients with breast cancer can receive various forms of medical therapy such as surgery, chemotherapy, hormone therapy, radiotherapy and may be confronted with adverse events. It can be assumed that treatment with chemotherapy certainly corresponds with more pronounced effects due to reported side effects, including hair loss, cardiotoxicity, and neurotoxicity $[14,24]$. Peripheral neuropathy $(\mathrm{PN})$ is one of the most common non-hematologic toxicities occurring among patients [25]. The severity and the prevalence of taxane-induced PN (TIPN) may still be underestimated in clinical routine assessments [26, 27].

More studies are needed that provide information on patients' perceived circumstances linked to routine cancer treatment regimes. Alongside the traditional clinical reports, transparency on performance-based outcome measures (OMs) is required to improve the quality of care $[28,29]$. Close monitoring patient's care pathway appears to be of particular relevance as the option to conduct a risk stratification becomes available. Further differentiation on the perception of disease and the detection of unmet supportive care needs could help to personalize and optimize clinical and survivorship care.

However, to date few studies have examined the effects of different routine cancer treatment regimens on the neuropsychological performance with the PPT of women with newly diagnosed breast cancer. The purpose of the present study was to find out the extent to which performance-based OMs change over the course of the therapy. Based on this background, we conducted a study among 4 groups undergoing routine breast cancer treatment.

\section{Methods}

Between April 2018 and October 2020, a total of 149 patients with the first diagnosis of breast cancer were recruited within the research study, "RETURN" which was approved by the Ethics Committee of Chemnitz University of Technology (V-182-17-ASTumor-20012017) and registered with the German Clinical Trials Register (ID: DRKS00014263). All patients were recruited in the Red Cross Hospital in Chemnitz, Germany. Within 1 week after the diagnosis of breast cancer, affected women were invited by their doctor to a consultation and informed about possible participation in the present study. Participants had the opportunity to discuss their participation and read and consider the research information leaflet. Furthermore, sufficient time $(>24 \mathrm{~h})$ to reflect on the implications of participating in the study was given before the patients had to decide. Inclusion criteria for this analysis were patients freely given written informed consent to participate in the study, recent diagnosis of untreated breast cancer, age $<70$ years. Patients with breast cancer were excluded if they had a previous invasive malignancy, other malignant tumours, insufficiently treated pulmonary arterial hypertension, chronic obstructive pulmonary disease shown in Figure 1. Baseline demographics and patients' clinical characteristics were provided by the Clinical Cancer Registry Chemnitz (Tumorzentrum Chemnitz) (shown in Table 1). All assessments were carried out prior to (T0) and within 1 week after completing (T1) conventional cancer treatment (surgery, chemotherapy, and radiotherapy). The follow-up assessments were carried out 3 months after treatment (T2). Cases with long-term endocrine therapy continued beyond T2. Four treatment subgroups were included for the following analysis: $\mathrm{SC}=$ Surgery + Chemotherapy, SCR = Surgery + Chemotherapy + Radiotherapy, $S R=$ Surgery + Radiotherapy and $S=$ Surgery.

\section{Materials}

Assessment consisted of the PPT (Lafayette Instrument Co.; Model 32020A) following standardized directions for administration [30]. To evaluate the fine motor dexterity of the hands and fingers study participants were seated at a desk, and the Purdue Pegboard was placed in front of them. Participants were instructed to place as many pins and/or washers/collars as possible down the respective row in the given time interval prior to administering the $5 \mathrm{sub}$ tests: dominant hand $(\mathrm{DH})$, number of pins placed in $30 \mathrm{~s}$, non-dominant hand (NDH) number of pins placed in 30 $\mathrm{s}$, both hands $(\mathrm{BH})$, right + left + both $(\mathrm{R}+\mathrm{L}+\mathrm{B})$ number of pins placed in $30 \mathrm{~s}$ and assembly (ASSY), number of pins, washers, and collars placed in $60 \mathrm{~s}$. Each upper extremity was tested 3 times per session, and a mean score for each test was calculated. All assessments were performed by personnel trained examiners who administered all tests and documented all scores. The data analysis was performed with the statistical software package IBM SPSS statistics 26 (Chicago, IL, USA). Only those patients who completed all assessments were included in the analysis. Descriptive statistics are presented as mean, standard deviation (SD) of the outcome parameters. A significance level of $p<0.05$ for data analyses was set. To ensure comparability between the study groups, demographic characteristics (age, height, weight, and BMI) were tested using ANOVA. All metric data were normally distributed (Shapiro-Wilk test), and sphericity was identified (Mauchly test). There was homogeneity of the error variances (Levene's test). Group differences over time were investigated with simple main effects of the between-subjects factor (Tukey-HSD), and secondary outcome variables with a repeated measure ANOVA for simple main effects of the within-subject factor (Bonferroni). Treatment-specific interactions between time and group (Greenhouse-Geisser) were tested by applying the mixed ANOVA for significant effects and post hoc analysis (Tukey, Games-Howell). The effect size was calculated by using the formula:

$$
\text { partial } n^{2}=\frac{S S_{\text {effect }}}{\text { SSeffect }+ \text { SSerror }} \text {. }
$$

Grusdat/Stäuber/Tolkmitt/Schnabel/ Schubotz/Schulz 


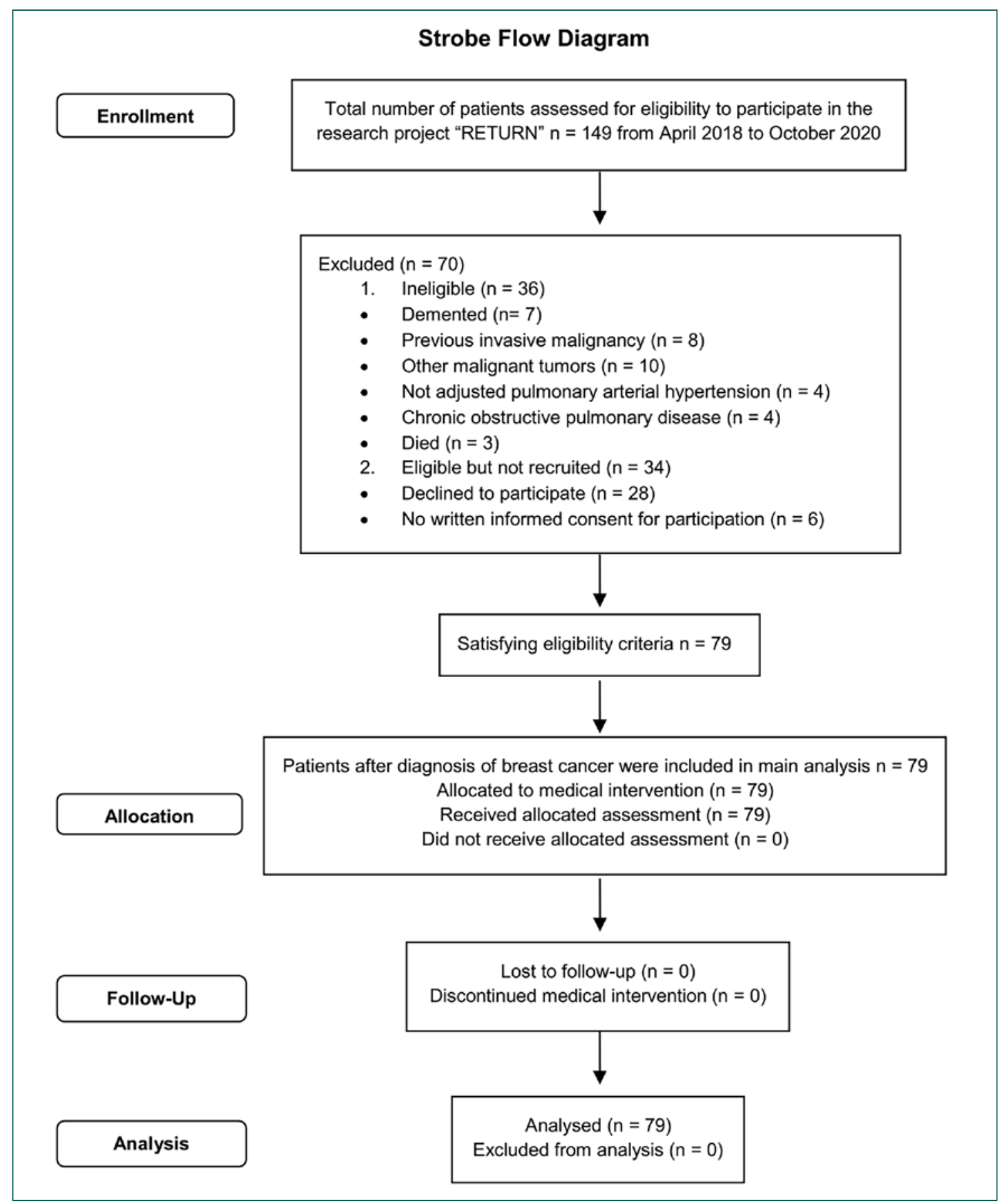

Fig. 1. STROBE flow diagram of the prospective observational study in women with breast cancer.

Suggested benchmarks for interpretation of the effect size are small (0.1-0.3), medium (0.3-0.5), and large $(>0.5)$ [31].

\section{Results}

Seventy-nine women with breast cancer were included in the present analysis. Mean (SD) age of the total sample at diagnosis was $54.6 \pm 9.5$ years (range $=30-69$ years).
ANOVA revealed comparability of demographic variables between the groups $(p>0.05)$. Mean (SD) time interval between diagnosis of breast cancer and initial data collection prior to starting treatment for breast cancer (T0) was $6.8 \pm 1.3$ days (range 6.0-9.0 days). For completing therapy all women with primary disease finished their cycles of chemotherapy, treatment sessions of radiotherapy and/or cancer surgery. Total mean (SD) time for completing therapy was $6.6 \pm 3.0$ months (range 1.0-13.4 months.). After breast cancer treatment, follow-up data 
Table 1. Baseline demographics and patients' clinical characteristics of $n=79$ women with breast cancer

\begin{tabular}{|c|c|c|c|c|}
\hline Variable & Group SC & Group SCR & Group SR & Group S \\
\hline$N(\%)$ & $22(27.9)$ & $17(21.5)$ & $27(34.2)$ & $13(16.5)$ \\
\hline Age, years & $51.9 \pm 11.6$ & $54.4 \pm 8.5$ & $56.7 \pm 9.0$ & $55.3 \pm 7.3$ \\
\hline Height, m & $1.65 \pm 0.08$ & $1.65 \pm 0.08$ & $1.61 \pm 0.06$ & $1.63 \pm 0.08$ \\
\hline Weight, kg & $72.1 \pm 14.2$ & $82.7 \pm 20.2$ & $68.6 \pm 12.4$ & $72.6 \pm 12.5$ \\
\hline BMI, $\mathrm{kg} \mathrm{m}^{-2}$ & $26.4 \pm 5.0$ & $30.5 \pm 6.8$ & $26.4 \pm 4.8$ & $27.4 \pm 4.3$ \\
\hline \multirow[t]{4}{*}{ UICC, $n$ (\%) } & IA: 5 (6.3) & IA: 7 (8.9) & IA: 25 (31.7) & IA: 5 (6.3) \\
\hline & IIA:10 (12.7) & IIA:7 (8.9) & IIA: 2 (2.5) & IIA: 8 (10.1) \\
\hline & IIIA: 1 (1.3) & IB: $2(2.5)$ & IB: $0(0.0)$ & IB: $0(0.0)$ \\
\hline & IIB: 6 (7.6) & IIB: 1 (1.3) & IIB: $0(0.0)$ & IIB: $0(0.0)$ \\
\hline Time of therapy, month & $7.7 \pm 1.3(6.0-10.5)$ & $10.4 \pm 1.6(7.1-13.4)$ & $5.3 \pm 1.5(3.0-9.3)$ & $2.5 \pm 1.6(1.0-5.6)$ \\
\hline SNB, $n(\%)$ & $21(26.6)$ & $15(19.0)$ & $27(34.2)$ & $13(16.5)$ \\
\hline ALND, $n$ (\%) & $5(6.3)$ & $3(3.8)$ & $0(0.0)$ & $0(0.0)$ \\
\hline $\mathrm{BCS}, n(\%)$ & $8(10.1)$ & $16(20.3)$ & $27(34.2)$ & $0(0.0)$ \\
\hline MRM, $n(\%)$ & $2(2.5)$ & $1(1.3)$ & $0(0.0)$ & $2(2.5)$ \\
\hline $\mathrm{SCM}, n(\%)$ & $9(11.4)$ & $0(0.0)$ & $0(0.0)$ & $10(12.7)$ \\
\hline $\mathrm{BCS}+\mathrm{SCM}, n(\%)$ & $3(3.8)$ & $0(0.0)$ & $0(0.0)$ & $1(1.3)$ \\
\hline TMX, $n(\%)$ & $1(1.3)$ & $4(5.1)$ & $6(7.6)$ & $1(1.3)$ \\
\hline ALs, $n(\%)$ & $13(16.5)$ & $9(11.4)$ & $20(25.3)$ & $11(13.9)$ \\
\hline Anth-bCTx, $n$ (\%) & $12(15.2)$ & $9(11.4)$ & $0(0.0)$ & $0(0.0)$ \\
\hline TaxAnth-C, $n$ (\%) & $10(12.7)$ & $8(10.1)$ & $0(0.0)$ & $0(0.0)$ \\
\hline $\mathrm{R}, n(\%)$ & $0(0.0)$ & $17(21.5)$ & $27(34.2)$ & $0(0.0)$ \\
\hline
\end{tabular}

Data are expressed as means \pm SD; $n=$ number of patients (\%). SC, Surgery + Chemotherapy; SCR, Surgery + Chemotherapy + Radiotherapy; SR, Surgery + Radiotherapy; S, Surgery; ALND, Axillary lymph node dissection; ALs, Aromatase inhibitors; Anth-bC, Anthracycline-Based Chemotherapy; BCS, Breast-conserving surgery; MRM, Modified Radical Mastectomy; R, Radiotherapy; SCM, Subcutaneous mastectomy; SNB, Sentinel node biopsy; TMX, Tamoxifen; TaxAnth-C, Anthracycline-Taxane-Based Chemotherapy; SD, standard deviation.

were collected within 1 week (mean $5.7 \pm 0.8$ days, range 4.0-7.0). The second follow-up took place 3 months after T1 (mean $91.4 \pm 1.5$ days, range 86.0-97.0). The statistical comparison of the data is summarized in Table 2. The longitudinal comparison indicated significant main effect (time) for the parameters: $\mathrm{DH}(F[1.55,116.63]=$ $\left.57.76 p<0.001, \eta^{2}=0.44\right), \mathrm{NDH}(F[1.69,126.34]=63.13$ $\left.p<0.001, \eta^{2}=0.46\right)$, BH $(F[1.86,139.81]=163.80 p<$ $\left.0.001, \eta^{2}=0.69\right)$, and ASSY $(F[1.88,140.64]=140.37 p<$ $\left.0.001, \eta^{2}=0.65\right)$. The highest effect sizes were shown in $\mathrm{BH}$ and ASSY (large effect).

A significant group $\times$ time interaction was shown for $\mathrm{DH}\left(F[4.67,116.62]=5.59, p<0.001, \eta^{2}=0.18\right), \mathrm{NDH}(F$ $\left.[5.05,126.34]=6.61, p<0.001, \eta^{2}=0.21\right), \mathrm{BH}(F[5.59$, $\left.139.81]=13.11 p<0.001, \eta^{2}=0.34\right)$, and ASSY $(F[5.63$, $\left.140.64]=5.84 p<0.001, \eta^{2}=0.19\right)$ as significantly greater restrictions were experienced in the SC and the SCR group compared to the SR and the S group. The effect sizes for the primary outcome variable were small to moderate.

\section{Discussion/Conclusion}

Based on the preliminary data of the research study "RETURN", we conducted a sub-analysis of neuropsychological OMs in women with breast cancer. This study is the first to perform a detailed characterization of the PPT in regard to the routine cancer treatment regimens. For monitoring of the neuropsychological performance in the early time course of breast cancer treatment, the clinically established PPT was used prior (T0) and post-cancer treatment (T1, T2). Our main findings provide evidence that women with breast cancer showed impaired hand and finger function immediately following cancer treatment and at 3-month follow-up. Across all treatment groups, the most pronounced impact was found in the SCR group following multi-modular treatment. Women with breast cancer who were exposed to chemotherapy performed worse in the 5 subtests of the PPT than patients of S and SR group.

Using PPT to evaluate changes of fine motor dexterity, we found that treatment subgroups in the present study showed 3-12\% lower values in the ASSY subtest prior to cancer treatment than reference norms of healthy women aged 50-59 years [10, 30]. Differences at baseline could be based on emotional distress associated with the breast cancer diagnosis causing disrupted functional dynamics [32, 33]. Moreover, sex and age regarding guideline values for the Purdue Pegboard (3 Trials per Subtest) $[10,30]$ were undercut by our study groups to varying degrees $\mathrm{T} 1 ; \mathrm{DH}$ (SC - 9\%, SCR -9\%, SR -3\%, S -3\%), NDH (SC - 9\%, SCR $-10 \%$, SR $-1 \%$, S $-3 \%$ ), BH (SC $-12 \%$, SCR $-11 \%$, SR $+2 \%$, $\mathrm{S}-1 \%$ ) and in ASSY (SC $-22 \%$, SCR $-14 \%$, SR $-15 \%, \mathrm{~S}$
40

Oncol Res Treat 2022;45:37-44

DOI: $10.1159 / 000519829$
Grusdat/Stäuber/Tolkmitt/Schnabel/ Schubotz/Schulz 


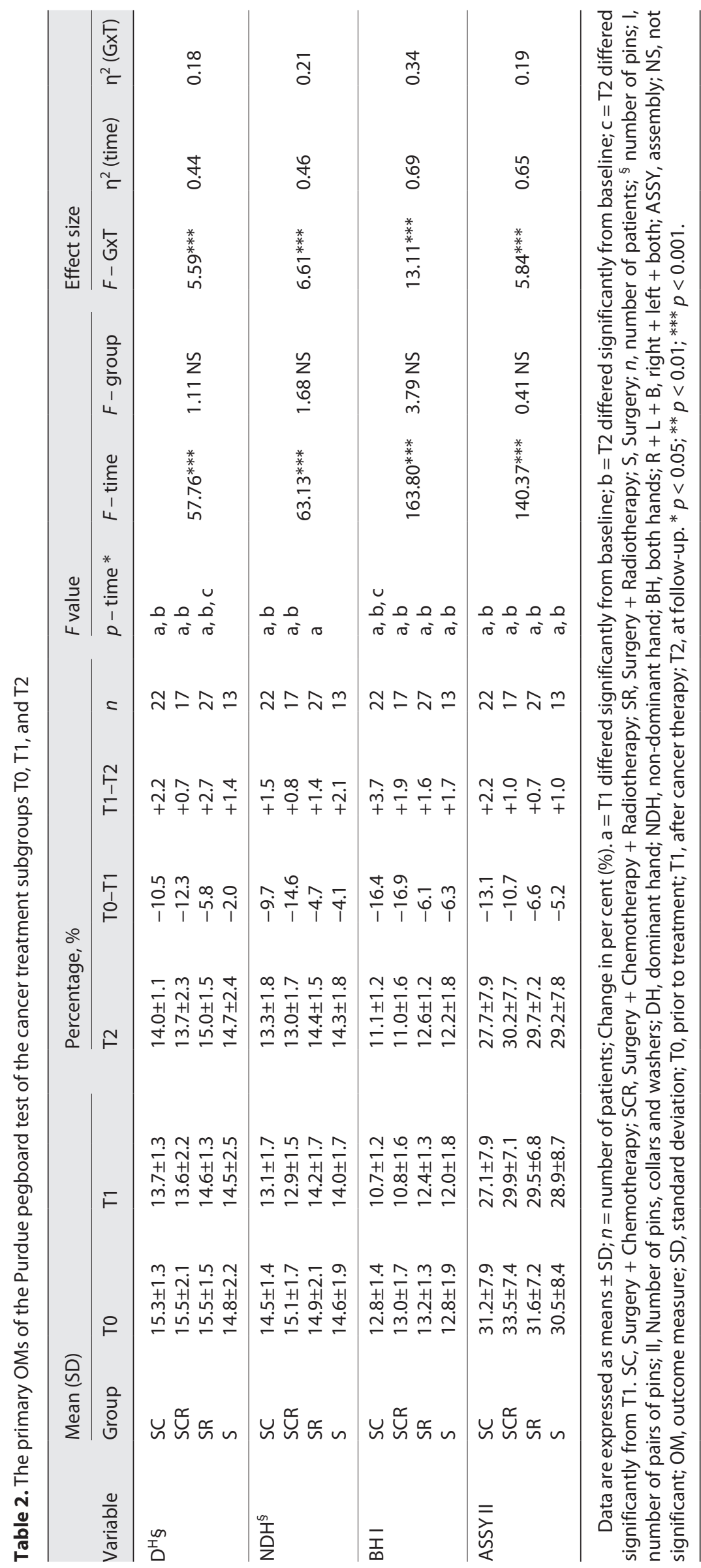


$-16 \%)$ which may be associated with changes in cognitive, sensory, and motor functions [10, 34]. Underlying mechanisms resulting in lower performance of the PPT in our study participants might be influenced by the state of inflammatory tumour $[20,35]$, the effect of anaesthetic drugs received [36], changes in hormone levels [37-39], attentional fatigue and neurotransmitter deregulation [40-42].

Our findings of strongest performance impairments within the chemotherapy-exposed groups may be related to neurotoxicity causing neurologic damage [43, 44], CRCI $[9,45]$, and interhemispheric transfer deficits [46]. However, the cause of the defect often remains undefined and is still not fully understood. Nevertheless, patients can get overwhelmed by impaired functional abilities and concurrent-related symptoms, including tingling, burning pain, and paraesthesia $[47,48]$. The PPT is a reliable and time-efficient measure that can be helpful in identifying limitations for hand dexterity. There is a considerable amount of research available in support of its use in clinical practice and research [49-51]. The manual provides detailed directions, scoring, and reference norms across the lifespan (ages 5-89 years old) [10, 30], which makes the conduction of routine assessment in large target groups possible. The PPT is easily applicable for an oncology nurse as no special training is required and due to the portable use in a variety of settings. Based on the quick feasibility, long-term monitoring in survivorship care may be advantageous. Along with nerve conduction velocity testing, medical complications can be minimized by providing adequate intervention [52].

The total mean scores of SCR and SC group at T1 are similar to previously reported $\mathrm{DH} 13.8, \mathrm{NDH} 12.9$, and $\mathrm{BH} 11.1$ values in women with breast cancer $>20$ years after adjuvant chemotherapy $(n=196)$ [11]. It transpired that women need to receive information about the possible effects of memory loss and advice about coping methods. Additionally, concerns on completing education or being able to meet job requirements to secure financial stability are debilitating and signal an adverse effect [53]. Follow-up data of our study participants may be an indicator of a lower capacity during everyday life [54] which requires therapeutic alignment to prevent deterioration of conditions $[55,56]$. Further, survivors of breast cancer exposed to paclitaxel or docetaxel chemotherapy more often reported PN [57]. The management of CIPN [58] can be particularly severe and long-lasting [59]. Furthermore, CIPN may affect the quality of life to such an extent that a drug dose reduction is required [60]. This is accompanied by a potentially higher risk of mortality and morbidity due to the discontinuation of initial cancer treatment [61, 62]. Early implementation of regular exercise interventions of walking and resistance training, individually adapted to fitness with moderate-intensity counteracted illness-related symptoms in patients receiv- ing taxane-based chemotherapy [63]. However, the evidence of studies focussing on improving CIPN and CRCI with exercise treatment is limited $[64,65]$. In the light of apparent CIPN and CRCI, study designs must employ baseline assessments of PPT to detect changes accurately. More research is needed to identify how clinical characteristics, including older age, obesity, dietary supplements, stage of cancer, and side effects of chemotherapy, contribute to an increased risk of impaired fine motor skills. Assessing the fine motor dexterity should be integrated as a common measure in treatment process of women with breast cancer for advanced classifications. Performance-based OMs may give guidance to healthcare professionals as well as the team involved including oncologists, physiotherapists, and nurses for determining individualized needs of women with breast cancer and to initiate the appropriate supportive care, which may lead to better health outcomes and should thus be explored. For a beneficial approach in the subsequent oncological rehabilitation treatment, the optimal treatment modalities and timing for their implementation are required.

\section{Limitations}

There are limitations to the present study as we could not include an additional follow-up analysis. Since the number of patients, especially in group $\mathrm{S}$ was small $(n=$ 13), our findings can only be regarded as preliminary, and future investigations are necessary for the generalizability of our findings. Treatment groups may not be representative for all cancer patients and especially not for those with a severe course of illness. Based on treatment regimens, differently distributed variables of clinical characteristics appeared in the final sample of patients. A multivariable risk-stratified approach with a larger sample size for identifying reduced fine motor dexterity is necessary. Socioeconomic status as a possible influencing factor was not investigated. Screening patients for their levels of physical activity throughout the course of therapy may have led to a more differentiated assumption of study results.

\section{Conclusion}

In summary, women with breast cancer showed decreased unimanual and bimanual dexterity and across all groups, with the most pronounced impact in the SCR and SC group following a multi-modal treatment. Differences were particularly noticeable in the reduced performance with their $\mathrm{NDH}$, their $\mathrm{DH}$, with $\mathrm{BH}$, and in ASSY. In order to strengthen health resources, especially for women undergoing combined cancer treatment, a multidisciplinary support is necessary. A permanent adoption of performance-based OMs in clinical research may increase the transparency of the patients' perceived circum-
Grusdat/Stäuber/Tolkmitt/Schnabel/ Schubotz/Schulz 
stances. Routine assessment may help to personalize and optimize clinical and survivorship care and improve the overall patient's experience.

\section{Statement of Ethics}

Study approval statement: This study was performed in line with the principles of the Declaration of Helsinki. Approval was granted by the Ethical Review Board of Chemnitz University of Technology (reference number: V-182-17-AS-Tumor-20012017). The RETURN study is registered with the German Clinical Trials Register (ID: DRKS00014263).

Consent to participate statement: Written informed consent was obtained from all individual participants included in this study.

Consent for publication: N/A.

\section{Conflict of Interest Statement}

The author(s) declared no potential conflicts of interest with respect to the research, authorship, and/or publication of this article.

\section{Funding Sources}

This study was not supported by any funding.

\section{Author Contributions}

N.P.G. performed data collection, management, analysis, and manuscript writing; A.S. helped in data analysis and manuscript editing and provided scientific oversight for the manuscript; M.T. and J.S. helped in data collection; B.S. supplied clinical data and performed data management; H.S. provided editorial assistance for the manuscript. All the authors have read and approved the final manuscript.

\section{Data Availability Statement}

The datasets used and/or analysed during the current study are available from the corresponding author on reasonable request.

\section{References}

1 Ferlay J, Colombet M, Soerjomataram I, Parkin DM, Piñeros M, Znaor A, et al. Cancer statistics for the year 2020: an overview. Int J Cancer. 2021 Apr 5. Epub ahead of print.

2 European Commission. Breast cancer burden in EU-27. European cancer information system. 2020. Available from: https://ecis.jrc. ec.europa.eu/pdf/Breast_cancer_factsheetDec_2020.pdf Accessed 2021 Apr 14.

3 The Global Cancer Observatory. Switzerland. 2021. Available from: https://gco.iarc.fr/today/data/factsheets/populations/756-switzerland-fact-sheets.pdf Accessed 2021 Jun 16.

4 Barnes B, Kraywinkel K, Nowossadeck E, Schönfeld I, Starker A, Wienecke A, et al. Bericht zum Krebsgeschehen in Deutschland 2016. Robert Koch-Institut; 2016.

5 Thorn DR, Ladewig Hess AR. Outpatient breast cancer treatment after the hospital: what's next? - Adjuvant medical therapies, management of side effects and common fears, planing and coordination of optimal follow-up care in view of current guidelines. Ther Umsch. 2021;78(3):136-44.

6 Kubo Y, Naito T, Mori K, Osawa G, Aruga E. Skeletal muscle loss and prognosis of breast cancer patients. Support Care Cancer. 2017; 25(7):2221-7.

7 Ten Tusscher MR, Groen WG, Geleijn E, Sonke GS, Konings IR, Van der Vorst MJ, et al. Physical problems, functional limitations, and preferences for physical therapist-guided exercise programs among Dutch patients with metastatic breast cancer: a mixed methods study. Support Care Cancer. 2019;27(8): 3061-70.

8 Lindstrom-Hazel DK, VanderVlies Veenstra N. Examining the Purdue pegboard test for occupational therapy practice. Open J Occup Ther. 2015;3(3):5.
9 Ono M, Ogilvie JM, Wilson JS, Green HJ, Chambers SK, Ownsworth T, et al. A metaanalysis of cognitive impairment and decline associated with adjuvant chemotherapy in women with breast cancer. Front Oncol. 2015;5:59.

10 Agnew J, Bolla-Wilson K, Kawas C, Bleecker M. Purdue pegboard age and sex norms for people 40 years old and older. Dev Neuropsychol. 1988;4(1):29-35.

11 Koppelmans V, Breteler MM, Boogerd W, Seynaeve C, Gundy C, Schagen SB. Neuropsychological performance in survivors of breast cancer more than 20 years after adjuvant chemotherapy. J Clin Oncol. 2012;30(10):10806.

12 Hoogendam YY, Schagen SB, Ikram MA, Boogerd W, Seynaeve C, Seidler RD, et al. Late effects of adjuvant chemotherapy for breast cancer on fine motor function. Psychooncology. 2015;24(12):1799-807.

13 Bao T, Basal C, Seluzicki C, Li SQ, Seidman $\mathrm{AD}$, Mao JJ. Long-term chemotherapy-induced peripheral neuropathy among breast cancer survivors: prevalence, risk factors, and fall risk. Breast Cancer Res Treat. 2016;159(2): 327-33.

14 Montemurro F, Mittica G, Cagnazzo C, Longo V, Berchialla P, Solinas G, et al. Self-evaluation of adjuvant chemotherapy-related adverse effects by patients with breast cancer. JAMA Oncol. 2016;2(4):445-52.

15 Riaz M, Vangberg TR, Vasylenko O, CastroChavira S, Gorecka MM, Waterloo K, et al. What does hand motor function tell us about our aging brain in association with WMH? Aging Clin Exp Res. 2021;33:1577-84.

16 Bakhshipour E, Koiler R, Milla K, Getchell N. Understanding the cognitive demands of the purdue pegboard test: an fNIRs Study. In: In- ternational Conference on Applied Human Factors and Ergonomics. Springer; 2020. p. 55-61.

17 van der Willik KD, Jóźwiak K, Hauptmann M, van de Velde EE, Compter A, Ruiter R, et al. Change in cognition before and after noncentral nervous system cancer diagnosis: a population-based cohort study. Psychooncology. 2021. Epub ahead of print.

18 Nyrop KA, Deal AM, Reeder-Hayes KE, Shachar SS, Reeve BB, Basch E, et al. Patientreported and clinician-reported chemotherapy-induced peripheral neuropathy in patients with early breast cancer: current clinical practice. Cancer. 2019;125(17):2945-54.

19 Lehoux C, Everett J, Laplante L, Émond C, Trépanier J, Brassard A, et al. Fine motor dexterity is correlated to social functioning in schizophrenia. Schizophr Res. 2003;62(3): 269-73.

20 van der Willik KD, Koppelmans V, Hauptmann M, Compter A, Ikram MA, Schagen SB. Inflammation markers and cognitive performance in breast cancer survivors 20 years after completion of chemotherapy: a cohort study. Breast Cancer Res. 2018;20(1):135-10.

21 Lang AE, Dickerson CR, Kim SY, Stobart J, Milosavljevic S. Impingement pain affects kinematics of breast cancer survivors in workrelated functional tasks. Clin Biomech. 2019; 70:223-30.

22 Miaskowski C, Mastick J, Paul SM, Topp K, Smoot B, Abrams G, et al. Chemotherapy-induced neuropathy in cancer survivors. J Pain Symptom Manage. 2017;54(2):204-18.e2.

23 Heitzer AM, Ashford JM, Hastings C, Liu APY, Wu S, Bass JK, et al. Neuropsychological outcomes of patients with low-grade glioma diagnosed during the first year of life. J Neurooncol. 2019;141(2):413-20. 
24 Ibrahim EY, Domenicano I, Nyhan K, Elfil M, Mougalian SS, Cartmel B, et al. Cognitive effects and depression associated with taxanebased chemotherapy in breast cancer survivors: a meta-analysis. Front Oncol. 2021;11: 642382 .

25 Rivera DR, Ganz PA, Weyrich MS, Bandos H, Melnikow J. Chemotherapy-associated peripheral neuropathy in patients with earlystage breast cancer: a systematic review. J Nat Cancer Inst. 2018;110(2):djx140.

26 Song SJ, Min J, Suh SY, Jung SH, Hahn HJ, Im $\mathrm{SA}$, et al. Incidence of taxane-induced peripheral neuropathy receiving treatment and prescription patterns in patients with breast cancer. Support Care Cancer. 2017;25(7):2241-8.

27 Kanzawa-Lee GA, Knoerl R, Donohoe C, Bridges CM, Smith EML. Mechanisms, predictors, and challenges in assessing and managing painful chemotherapy-induced peripheral neuropathy. Semin Oncol Nurs. 2019;35: 253-60. Elsevier.

28 Pappot H, Baeksted CW, Nissen A, Knoop A, Mitchell SA, Christensen J, et al. Clinical effects of assessing electronic patient-reported outcomes monitoring symptomatic toxicities during breast cancer therapy: a nationwide and population-based study. Breast Cancer. 2021;28(5):1096-99.

29 Kowalski C, Graeven U, von Kalle C, Lang H, Beckmann MW, Blohmer JU, et al. Shifting cancer care towards multidisciplinarity: the cancer center certification program of the German Cancer Society. BMC Cancer. 2017; 17(1):850-9.

30 Lafayette Instrument Company. Purdue pegboard test user instructions. Rel. 3.19.21. 2021. Available from: http://www.limef.com/ downloads/MAN-32020A-forpdf-rev1.pdf 2021 Jun.

31 Bakeman R. Recommended effect size statistics for repeated measures designs. Behav Res Methods. 2005;37(3):379-84.

32 Tang L, Fritzsche K, Leonhart R, Pang Y, Li J, Song L, et al. Emotional distress and dysfunctional illness perception are associated with low mental and physical quality of life in Chinese breast cancer patients. Health Qual Life Outcomes. 2017;15(1):231-10.

33 Kesler SR, Adams M, Packer M, Rao V, Henneghan AM, Blayney DW, et al. Disrupted brain network functional dynamics and hyper-correlation of structural and functional connectome topology in patients with breast cancer prior to treatment. Brain Behav. 2017; 7(3): $\mathrm{e} 00643$.

34 Lezak MD. Norms for growing older. Taylor \& Francis; 1987.

35 Bender CM, Sereika SM, Ryan CM, Brufsky AM, Puhalla S, Berga SL. Does lifetime exposure to hormones predict pretreatment cognitive function in women before adjuvant therapy for breast cancer? Menopause. 2013; 20(9):922.

36 Bilotta F, Evered LA, Gruenbaum SE. Neurotoxicity of anesthetic drugs: an update. Curr Opin Anaesthesiol. 2017;30(4):452-7.
37 Bluethmann SM, Alfano CM, Clapp JD, Luta G, Small BJ, Hurria A, et al. Cognitive function and discontinuation of adjuvant hormonal therapy in older breast cancer survivors: CALGB 369901 (Alliance). Breast Cancer Res Treat. 2017;165(3):677-86.

38 Underwood EA, Rochon PA, Moineddin R, Lee PE, Wu W, Pritchard KI, et al. Cognitive sequelae of endocrine therapy in women treated for breast cancer: a meta-analysis. Breast Cancer Res Treat. 2018;168(2):299310 .

39 Jenkins V, Atkins L, Fallowfield L. Does endocrine therapy for the treatment and prevention of breast cancer affect memory and cognition? Eur J Cancer. 2007;43(9):1342-7.

40 Miller AH, Ancoli-Israel S, Bower JE, Capuron L, Irwin MR. Neuroendocrine-immune mechanisms of behavioral comorbidities in patients with cancer. J Clin Oncol. 2008;26(6): 971

41 Kohler C, Chang M, Allemann-Su YY, Vetter $M$, Jung $M$, Jung $M$, et al. Changes in attentional function in patients from before through 12 months after breast cancer surgery. J Pain Symptom Manage. 2020;59(6): 1172-85.

42 Eshragh J, Dhruva A, Paul SM, Cooper BA, Mastick J, Hamolsky D, et al. Associations between neurotransmitter genes and fatigue and energy levels in women after breast cancer surgery. J Pain Symptom Manage. 2017;53(1): 67-84.e7.

43 Dugdale AE, Chandler D, Jeffery H. Rapid repeated finger tapping. Aust Paediatr J. 1980; 16(3):175-6.

44 Sałat K. Chemotherapy-induced peripheral neuropathy - part 2: focus on the prevention of oxaliplatin-induced neurotoxicity. Pharmacol Rep. 2020;72(3):508-27.

45 Ahles TA, Root JC, Ryan EL. Cancer-and cancer treatment-associated cognitive change: an update on the state of the science. J Clin Oncol. 2012;30(30):3675.

46 Tao L, Wang L, Chen X, Liu F, Ruan F, Zhang J, et al. Modulation of interhemispheric functional coordination in breast cancer patients receiving chemotherapy. Front Psychol. 2020; 11:1689.

47 Reyes-Gibby CC, Morrow PK, Buzdar A, Shete $\mathrm{S}$. Chemotherapy-induced peripheral neuropathy as a predictor of neuropathic pain in breast cancer patients previously treated with paclitaxel. J Pain. 2009;10(11):1146-50.

48 Beijers AJ, Mols F, Tjan-Heijnen VC, Faber CG, van de Poll-Franse LV, Vreugdenhil G. Peripheral neuropathy in colorectal cancer survivors: the influence of oxaliplatin administration. Results from the population-based PROFILES registry. Acta Oncol. 2015;54(4): 463-9.

49 Traunwieser T, Kandels D, Pauls F, Pietsch T, Warmuth-Metz M, Bison B, et al. Long-term cognitive deficits in pediatric low-grade glioma (LGG) survivors reflect pretreatment conditions - report from the German LGG studies. Neuro Oncol Adv. 2020;2(1):vdaa094

50 Lawson I. Purdue pegboard test. Occup Med. 2019;69(5):376-7.

51 Tiffin J, Asher EJ. The Purdue pegboard: norms and studies of reliability and validity. J Appl Psychol. 1948;32(3):234.
52 Timmins HC, Li T, Kiernan MC, Baron-Hay S, Marx G, Boyle F, et al. Taxane-induced peripheral neuropathy: differences in patient report and objective assessment. Support Care Cancer. 2020;28(9):4459-66.

53 Boykoff N, Moieni M, Subramanian SK. Confronting chemobrain: an in-depth look at survivors' reports of impact on work, social networks, and health care response. J Cancer Surviv. 2009;3(4):223-32.

54 Cox-Martin E, Trahan LH, Cox MG, Dougherty PM, Lai EA, Novy DM. Disease burden and pain in obese cancer patients with chemotherapy-induced peripheral neuropathy. Support Care Cancer. 2017;25(6):1873-9.

55 Lyons KD, Svensborn IA, Kornblith AB, Hegel MT. A content analysis of functional recovery strategies of breast cancer survivors. OTJR. 2015;35(2):73-80.

56 Wirtz P, Baumann FT. Physical activity, exercise and breast cancer - what is the evidence for rehabilitation, aftercare, and survival? a review. Breast Care. 2018;13(2):92-100.

57 Ali MM, Moeller M, Rybicki L, Moore HC. Long-term peripheral neuropathy symptoms in breast cancer survivors. Breast Cancer Res Treat. 2017;166(2):519-26.

58 Hershman DL, Lacchetti C, Dworkin RH, Lavoie Smith EM, Bleeker J, Cavaletti G, et al. Prevention and management of chemotherapy-induced peripheral neuropathy in survivors of adult cancers: American Society of Clinical Oncology clinical practice guideline. J Clin Oncol. 2014;32(18):1941-67.

59 Bennion AE, Molassiotis A. Qualitative research into the symptom experiences of adult cancer patients after treatments: a systematic review and meta-synthesis. Support Care Cancer. 2013;21(1):9-25.

60 Dhawan S, Andrews R, Kumar L, Wadhwa S, Shukla G. A randomized controlled trial to assess the effectiveness of muscle strengthening and balancing exercises on chemotherapy-induced peripheral neuropathic pain and quality of life among cancer patients. Cancer Nurs. 2020;43(4):269-80.

61 Miltenburg NC, Boogerd W. Chemotherapyinduced neuropathy: a comprehensive survey. Cancer Treat Rev. 2014;40(7):872-82.

62 Scatchard K, Lee SM. Neurotoxicity of chemotherapy. In: Blue books of neurology. Elsevier; 2010. Vol. 36; p. 352-71.

63 Kleckner IR, Kamen C, Gewandter JS, Mohile NA, Heckler CE, Culakova E, et al. Effects of exercise during chemotherapy on chemotherapy-induced peripheral neuropathy: a multicenter, randomized controlled trial. Support Care Cancer. 2018;26(4):1019-28.

64 Majithia N, Temkin SM, Ruddy KJ, Beutler AS, Hershman DL, Loprinzi CL. National Cancer Institute-supported chemotherapyinduced peripheral neuropathy trials: outcomes and lessons. Support Care Cancer. 2016;24(3):1439-47.

65 Cai H, Li G, Hua S, Liu Y, Chen L. Effect of exercise on cognitive function in chronic disease patients: a meta-analysis and systematic review of randomized controlled trials. Clin Interv Aging. 2017;12:773. 